\title{
Where He Stood: Schulze's Portfolio
}

Marvin Bell

The Iowa land rolls and turns like the human body. Surprise, California! Surprise, New York! You out there have giants among you, mountains and skyscrapers to point to heaven. We have a flower in the moonlight, a river that goes black, a park's worth of trees that form-up like a herd of cows, a silence the high winds pass without disturbing. We have a meadow of ivory, what snow turns to in our own gray. We have a spindly aspen on which every leaf is a message. We have a lacy weaving in the winter and a thaw in the spring you can see coming. The work gets done in the morning and the afternoon. Anything you say can go to find its echo, and love can go a long way where any eye can reach the horizon.

Because a tree is more important if you only have one. Because undulation is a slow movement in the mind that sees the land underfoot, not just a crossing. Because less is still more, three better than four, one over two.

Composition is something. We can ask where the photographer stood, but not why. Recognition is more of it, and subsumes composition. What do we recognize in the wordless world where we seek, inevitably, ourselves? Why take it down? Where did the photographer stand?

Time comes into it, may be all of it. A place may have a certain look three minutes a year, all things going one way. It will do no good to go over and over it. Those images which arrive, arrive at once. Words work another way, but have told of it. Emily Dickinson wrote, "There's a certain Slant of light," and found the sense it made: "... internal difference, / Where the Meanings, are."

These landscapes are different from many: little anthropomorphization, not much blatant mirroring, tones of gradation given an importance beyond forms, usually a levelling plane visible from here to there. Much is silvery, crystalline. 
The curved eye wants to fit into the sky. Even in the snow, even in the water. It's a Midwest low-line, a report heading toward belief. Outside. Apart. Alone. Not lonely.

So you know where we stand.

\section{Classified}

I am no more stupid now than I ever was; I am the same. The end of tomorrow is no further away than it ever was. If no one had occasionally moved them, or fuelled them, the end of our todays would be frozen like a field of old bolts in their military silos, and wouldn't that be a kick in the flowers for all the earthshaking dreams that caught us. Wanted: a few good men and women who won't do their jobs. 